\title{
Use of Factory-Waste Shingles and Cement Kiln Dust to Enhance the Performance of Soil Used in Road Works
}

\author{
Aly Ahmed, Medhat Shehata, and Said Easa \\ Department of Civil Engineering, Ryerson University, 350 Victoria Street, Toronto, ON, Canada M5B 2K3 \\ Correspondence should be addressed to Medhat Shehata, mshehata@ryerson.ca
}

Received 6 July 2009; Revised 30 October 2009; Accepted 14 December 2009

Recommended by Ghassan Chehab

\begin{abstract}
An experimental work was conducted to study the use of factory-waste roof shingles to enhance the properties of fine-grained soil used in road works. Cement kiln dust (CKD), a cogenerated product of Portland cement manufacturing, was used as a stabilizing agent while the processed shingles were added to enhance the soil tensile strength. The effects of shingles on strength and stability were evaluated using the unconfined compressive strength, splitting tensile strength, and California Bearing Ratio (CBR) tests. The results showed that the use of CKD alone resulted in a considerable increase in the unconfined compressive strength but had a small effect on the tensile strength. The addition of shingles substantially improved the tensile strength of the stabilized soil. A significant reduction in the capillary rise and a slight decrease in the permeability were obtained as a result of shingle addition. An optimal shingle content of $10 \%$ is recommended to stabilize the soil.
\end{abstract}

Copyright ( $) 2009$ Aly Ahmed et al. This is an open access article distributed under the Creative Commons Attribution License, which permits unrestricted use, distribution, and reproduction in any medium, provided the original work is properly cited.

\section{Introduction}

Extensive research has been performed during the past two decades to protect the environment. The use of waste materials in construction applications has many environmental benefits including costs saving in terms of their disposal and potential recyclability. Examples of such waste materials include factory-waste roof shingles and cement kiln dust (CKD). Roof shingles are primarily composed of asphalt binder, hard rock granules/fillers, and fibers. There are two types of shingles: organic and glass. Organic shingles are made on a thick felt of wood and other cellulose fibers. Glass shingles are made on a mat of nonwoven glass fibers, which are held together with a water-insoluble binder. Organic shingles, which are the most commonly used asphalt shingles in Canada, contain more asphalt and are suitable for cold weather while glass shingles are more resistant to heat [1]. Cement kiln dust is a cogenerated product of Portland cement manufacturing. More than six million tons of postconsumer roofing shingles and about one million tons of preconsumer are generated in the USA annually [2]. 1.25 million scrap asphalt and saturated-felt shingles are generated from Canadian residential asphalt tear-off (reroofing) shingles, new construction scrap, and related organic-felt scrap quantities [3]. Most of the waste shingles are deposited in landfills, creating a sizable disposal problem and gradual loss of landfill space. On the other hand, about 12.90 million metric tons of CKD, that are not suitable for recycling, are disposed-off annually by cement manufacturing companies in Canada [4].

The industry has used shingles in road construction applications as a solution for the shingles accumulation problem. Prior to their use in construction, the waste shingles go through grinding and screening to the appropriate sizes, forming reclaimed asphalt shingles (RAS). Different stabilization methods have been used to enhance the performance of the geotechnical materials in highway construction. Generally, the cement-stabilized structure is weak in tension. Therefore, when this method is introduced as a reinforcing system, another material is usually added to resist tension. In pavement structures, since the pavement layers are subjected to repeated tensile stresses due to traffic loads, the splitting tensile strength is a vital property in these applications.

This paper investigates the feasibility of using both CKD as a stabilizing agent and factory-waste asphalt shingles to improve the properties of the fine soil that could constitute the subgrade of a flexible pavement or the fine fraction of the subbase. A brief description of previous research is 
TABLE 1: Physical and mechanical properties of fine grained soil.

\begin{tabular}{lclc}
\hline Property & Value & Property & Value \\
\hline Effective diameter, $\left(\mathrm{D}_{10}\right),(\mathrm{mm})$ & 0.10 & Max. dry unit weight, $\left(\mathrm{N} / \mathrm{mm}^{3}\right)$ & $1.99 e-5$ \\
Nominal mean size, $\left(\mathrm{D}_{50}\right),(\mathrm{mm})$ & 0.35 & Optimal moisture content, $(\%)$ & 9.00 \\
Uniformity coefficient, $(\mathrm{Cu})$ & 3.90 & Specific gravity, Gs & 2.78 \\
Curvature coefficient, $(\mathrm{Cc})$ & 1.30 & CBR (Unsoaked), $(\%)$ & 19.40 \\
Passing from sieve no. 200 & 5.00 & CBR (Soaked), $(\%)$ & 16.30 \\
Min. void ratio & 0.47 & Max. void ratio & 0.83 \\
\hline
\end{tabular}

first presented, followed by the materials and methods used in the study. The results of the lab experiments, including compressive and splitting tensile strengths, CBR, capillary rise, and permeability, are then presented.

\section{Previous Research}

The use of shingles in road construction focused in two areas: the asphaltic pavement layer and the subgrade. For asphaltic concrete applications, most of previous studies reported that the use of RAS in hot mix asphalt reduced the amount of the required virgin asphalt in addition to saving the cost of shingle disposal. Also a few studies investigated the use of RAS as a reinforcement to enhance the performance of the road materials $[5,6]$. Hooper and Allen [6] developed a composite material consisting of $10 \%$ RAS, 30\% recycled asphalt pavement (RAP), and 60\% gravel. The new composite material was placed and compacted on a series of municipal roads and sprayed with calcium chloride solution. Over a two-year period, the study reported that the shingle mix resisted rutting and erosion and required less maintenance than the conventional gravel-control sections.

Rajendran and Gambatese [7] investigated the use of different ratios of reclaimed polyethylene derived from waste plastic bags which was collected from domestic waste as additives in asphalt concrete pavement. The results indicated that the performance of the modified asphalt was better compared to conventional mixes. Adding 5\% of reclaimed polyethylene by weight of asphalt was recommended. Ibrahim et al. [8] investigated the performance of asphalt concrete mixes with different combinations of limestone and basalt aggregate. The asphalt concrete mix included basalt coarse aggregate, limestone fine aggregate, and mineral filler, and $1 \%$ hydrated lime was found to be the optimal mix. Kumar and Singh [9] investigated the use of fly ash reinforced with fibers as subbase material in rural road using static and dynamic load tests and semifield tests. The results showed that the use of fly ash reinforced with polypropylene fiber was suitable as subbase material in rural road construction.

CKD has been used in applications such as mineral filler in asphalt concrete mixes. In Japan, CKD was used to improve the rutting resistance of asphalt concrete pavements by absorbing the lighter fractions of excess asphalt binder [10]. Another study conducted by Thaha [4] investigated four different types of CKD as a replacement of Portland cement in the development of controlled low-strength material. The results showed that acceptable properties can be developed using different percentages of CKD [4].
The environmental effects on the durability of aggregates stabilized with CKD and other coetaneous material have been evaluated [11]. Generally adding a small amount of any cementation material increased the strength of the granular material, and this improvement increased when fibers are included.

For subgrade applications, several researchers have investigated the mechanical and physical properties of uncemented and cemented fine grained geotechnical material reinforced by different types of materials such as fibers, shredded tires, plastic waste, and geogrid elements [1219]. Hooper and Allen [6] investigated the mechanical and physical effects of adding RAS to soils. The authors used $25.4 \mathrm{~mm}$ RAS at different percentages by volume added to crushed stone that was used as base or subbase material. The RAS material was added to different soil types that represented the subgrade layer. The results showed that the added RAS affects the strength of the mixture as indicated by the CBR value. The improvement depended on the type of soil and the percentage of RAS material. Generally, the results indicated that adding RAS for weak plastic material (like clay) improved the strength, while for strong material (like sand and gravel) the added RAS diminished their strength.

The use of incinerated sewage sludge ash with cement as a stabilized agent to improve the strength of soft subgrade soil was investigated by Chen and Lin [20]. Five different ratios of the mixture of the additive were mixed with soft subgrade soil. The results indicated that the suggested mixture had a potential to improve the performance of soft subgrade soil. The CBR values for some samples treated with this mixture increased up to 30 times compared to untreated sample.

\section{Materials and Methods}

The stabilizing agents used in this study are CKD and RAS, which are co-generated products of Portland cement and roof shingles manufacturing, respectively. The materials were used to stabilize and enhance the properties of finegrained soil. The soil used is the fraction passing sieve no. $8(2.36 \mathrm{~mm})$ of the natural gravel materials used as subbase (Granular B) in Ontario. The grain size distribution for the tested soil is presented in Figure 1. This fraction also represents silty subgrade soil classified as poorly graded soil (SP) according to the Unified Soil Classification System. The physical and mechanical properties of the tested soil are shown in Table 1. It is known that the properties of CKD change considerably from one source to another depending on the physical, chemical, and phase composition. For this 


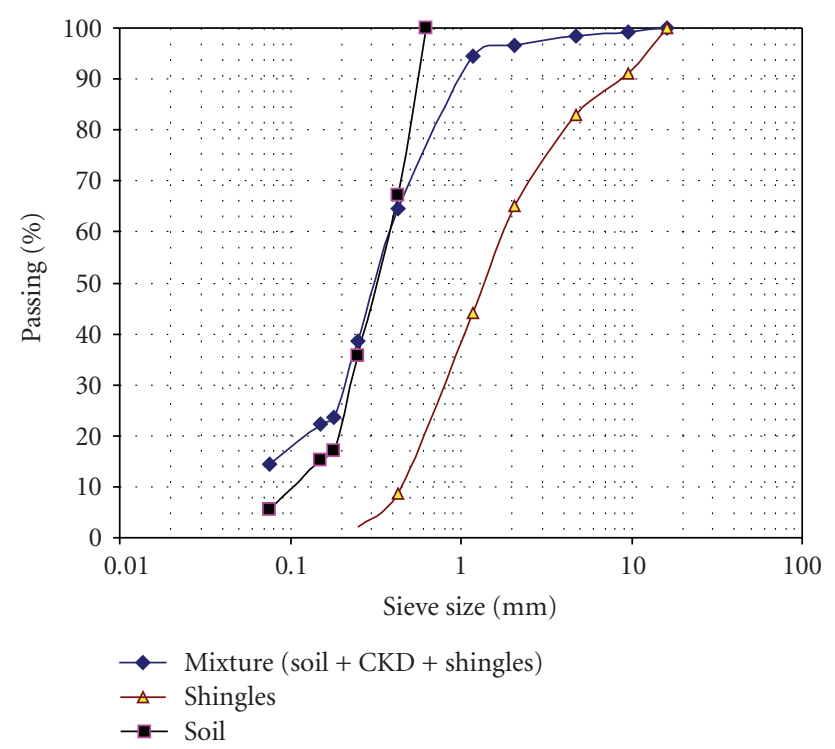

Figure 1: Particle size distributions for tested soil, shingles (RAS) and the combined Soil, RAS, and CKD.

TABLe 2: Chemical compositions of the different CKD.

\begin{tabular}{lccc}
\hline Chemical Composition & CKD1 & CKD2 & CKD3 \\
\hline Silicon Dioxide, $\left(\mathrm{SiO}_{2}\right)$ & 18.56 & 9.93 & 19.30 \\
Aluminum Oxide, $\left(\mathrm{Al}_{2} \mathrm{O}_{3}\right)$ & 5.51 & 3.38 & 5.02 \\
Ferric Oxide, $\left(\mathrm{Fe}_{2} \mathrm{O}_{3}\right)$ & 2.35 & 2.08 & 2.58 \\
Calcium Oxide, $(\mathrm{CaO})$ & 60.07 & 51.32 & 60.98 \\
Magnesium Oxide, $(\mathrm{MgO})$ & 2.37 & 1.60 & 2.64 \\
Sodium Oxide, $\left(\mathrm{Na}_{2} \mathrm{O}\right)$ & 0.23 & 0.23 & 0.30 \\
Potassium Oxide, $\left(\mathrm{K}_{2} \mathrm{O}\right)$ & 4.11 & 3.67 & 1.18 \\
Phosphorus Oxide, $\left(\mathrm{P}_{2} \mathrm{O}_{5}\right)$ & 0.14 & 0.09 & 0.16 \\
Titanium Oxide, $\left(\mathrm{TiO}_{2}\right)$ & 0.21 & 0.21 & 0.25 \\
Chloride, $(\mathrm{Cl})$ & 2.39 & - & - \\
Sulphur Trioxide, $\left(\mathrm{SO}_{3}\right)$ & 3.96 & 18.14 & 4.35 \\
Loss On Ignition & 15.23 & - & 3.10 \\
\hline
\end{tabular}

reason, three different CKD types, labelled as CKD1, CKD2, and $\mathrm{CKD} 3$, were used in this study to represent the range of the CKD properties available in North America. The chemical compositions of the three CKD types are shown in Table 2. Five levels of CKD content were investigated, namely $2.5 \%, 5 \%, 10 \%, 15 \%$, and $20 \%$ per mass of the soil.

The reclaimed asphalt shingles (RAS-Glass type) used in this research were a processed by-product resulting from a shingle manufacturer in Ontario, Canada. The processed shingle material was sieved and the fraction passing $3 / 8^{\prime \prime}$ or $9.5 \mathrm{~mm}$ sieve was used. The grain size distribution of the used shingle is presented in Figure 1 which also includes the gradation of the optimal percentages of the combined CKD, RAS, and Soil. Both RAS size and content as percentages of the soil mass were investigated to evaluate their effects on the soil properties and the feasibility of using shingles as a reinforcing material in highway construction. Four different shingle contents, namely, $5 \%, 10 \%, 15 \%$, and $20 \%$ by soil mass were investigated. For each shingle level, three different sizes were tested: large (passing $3 / 8^{\prime \prime}$ or $9.5 \mathrm{~mm}$ sieve and retained on sieve no. 4 , medium (passing sieve no. 4 and retained on sieve no. 8), and small (passing sieve no. 8). The effects of CKD and shingles on soil properties were evaluated, initially, using the unconfined compression and splitting tensile tests. All tests were conducted at the optimal moisture content and maximum dry unit weight. The tested samples are shown in Table 3. Cylindrical samples with a $50 \mathrm{~mm}$ diameter and $100 \mathrm{~mm}$ height were used. The tested soil and CKD were dry mixed and then the shingles were added to the mixture. After that, the optimal water content was added and mixing continued for 3 minutes. The samples were placed in the moulds and compacted statically using a hydraulic jack. Each cylinder contained the same volume of material so that the density of all tested samples was the same. Care was taken during sample preparation and extraction to produce homogenous samples. Three specimens were used for each test and the average result was used. All tests were conducted on samples after three days of curing at room temperature $\left(22 \pm 2^{\circ} \mathrm{C}\right)$ and $70 \%$ relative humidity. After evaluating the effects of shingles and CKD on soil strength, the California Bearing Ratio (CBR) test (both soaked and unsoaked) was conducted on samples containing only RAS to evaluate the effect of shingle size and content on the stability of the modified soil.

The effect of shingle size and content on the capillary rise was investigated to evaluate the effect of using shingles on the frost susceptibility of the soil. It is known that soils with high capillary rise are classified as frost susceptible since they provide the freezing front for the water to form ice lenses. Therefore, the rate of capillary rise of water was investigated for samples with different shingle sizes and contents, and $10 \%$ CKD. In addition, a control sample with $10 \%$ CKD and no shingles was investigated. The samples used in the capillary rise tests were of the same dimension and exposed to the same curing regime as the samples used in the strength tests. After completing the curing process, all samples were placed in a container over a plastic mesh with a thickness of $5 \mathrm{~mm}$ that is used as a support for the specimens. The container was then filled with water so that the water level is 1 to $3 \mathrm{~mm}$ above the top of the specimen support (plastic mesh) which is also the bottom of the specimens. The rise of water through the specimens was recorded visually until the water reached the top of the specimens. The effect of shingle size and content on the permeability of the stabilized soil was evaluated. Since the percentage of materials passing sieve no. $200(0.075 \mathrm{~mm})$ was less than $10 \%$, the hydraulic conductivity was tested using the Constant Head Method (ASTM D 2434).

\section{Results and Analysis}

4.1. Compressive and Splitting Tensile Strengths. To evaluate the effectiveness of different types of CKD on enhancing the strength of soil, compressive and splitting tests were conducted on a soil stabilized using 10\% CKD. This value was chosen in this preliminary investigation as a moderate level that can basically distinguish the efficacies among 
TAble 3: Experimental Program.

\begin{tabular}{|c|c|c|c|c|c|c|c|c|c|}
\hline \multirow{3}{*}{ Group test } & \multirow{3}{*}{ Test no. } & \multicolumn{4}{|c|}{ Unconfined compression test } & \multicolumn{4}{|c|}{ Splitting tensile test } \\
\hline & & \multicolumn{2}{|r|}{ CKD } & \multicolumn{2}{|c|}{ RAS } & \multicolumn{2}{|r|}{ CKD } & \multicolumn{2}{|c|}{ RAS } \\
\hline & & Type & Content $(\%)$ & Content $(\%)$ & Size & Type & Content (\%) & Content (\%) & Size \\
\hline \multirow{3}{*}{ A } & A-1 & 1 & 10 & \multirow{3}{*}{$-^{a}$} & \multirow{3}{*}{-} & 1 & 10 & \multirow{3}{*}{ - } & \multirow{3}{*}{ - } \\
\hline & A-2 & 2 & 10 & & & 2 & 10 & & \\
\hline & A-3 & 3 & 10 & & & 3 & 10 & & \\
\hline \multirow{5}{*}{ B } & B-1 & 2 & 2.5 & \multirow{5}{*}{-} & \multirow{5}{*}{-} & 2 & 2.5 & & \\
\hline & B-2 & 2 & 5 & & & 2 & 5 & & \\
\hline & B-3 & 2 & 10 & & & 2 & 10 & - & - \\
\hline & B-4 & 2 & 15 & & & 2 & 15 & & \\
\hline & B-5 & 2 & 20 & & & 2 & 20 & & \\
\hline \multirow{4}{*}{$\mathrm{C}$} & $\mathrm{C}-1$ & 2 & 10 & 5 & Small & 2 & 10 & 5 & Small \\
\hline & C-2 & 2 & 10 & 10 & Small & 2 & 10 & 10 & Small \\
\hline & C-3 & 2 & 10 & 15 & Small & 2 & 10 & 15 & Small \\
\hline & C-4 & 2 & 10 & 20 & Small & 2 & 10 & 20 & Small \\
\hline \multirow{3}{*}{$\mathrm{D}$} & D-1 & 2 & 10 & 10 & Small & 2 & 10 & 10 & Small \\
\hline & $\mathrm{D}-2$ & 2 & 10 & 10 & Medium & 2 & 10 & 10 & Medium \\
\hline & D-3 & 2 & 10 & 10 & Large & 2 & 10 & 10 & Large \\
\hline
\end{tabular}

${ }^{a}$ Not applicable.

different types of CKD. The results are shown in Figure 2(a). As noted, CKD1 produced the best results, followed by CKD2 and CKD3. Since the efficacy of CKD in stabilizing soil is related to its chemical, physical, and mineralogical compositions, attempts were not made to explain the different behavior of the CKDs based solely on the available oxide composition listed in Table 2. The results demonstrate that CKD stabilization is weak in tension compared to compression. The results suggest that CKD can be used as an alternative material for Portland cement to stabilize soil. These results are consistent with other research work that used CKD material as a replacement for Portland cement in the development of controlled low strength material [4]. In the rest of the experimental program, CKD2 was used as it was considered to represent the average quality of the available CKD. The compressive and splitting tensile strengths for different samples comprising different levels of CKD2 are shown in Figure 2(b). It is clear that the compressive strength increases with the increase in CKD content. On the contrary, the increase in CKD content did not result in a noticeable increase in the tensile strength. It should be noted that since the investigated soil is cohesionless, its compressive and tensile strengths at $0 \% \mathrm{CKD}$ are considered to be zero.

The results presented in Figure 2 demonstrate the need for another material, in addition to $\mathrm{CKD}$, to enhance the tensile properties of the stabilized soil. It is not uncommon to introduce fibers to a soil to enhance its tensile strength. Therefore, in this study, asphalt shingle (RAS) was used as an alternative material for reinforcing fibers to increase the resistance of soil to tensile stresses. It is reasonable to assume that the mixture of the fine-grained soil, CKD, and shingle is isotropic with regard to the stress-strain properties. As mentioned earlier, three different sizes and four contents of shingles were used to study the feasibility of using shingles to enhance the tensile strength of soil. A CKD2 content of $10 \%$ was used in all the tested samples. The 10\% CKD was chosen to be able to see if the added RAS would have an additional improvement on the compressive strength of the stabilized soil. It was felt that the relatively high compressive strength obtained with CKD levels larger than 10\% could mask or overwhelm any improvement that the RAS could have on the compressive strength. The effects of shingle on both compressive and tensile strengths are shown in Figure 3(a). Note that only medium size shingles were used. It can be seen that all shingle levels increased both tensile and compressive strengths compared to those of the samples without shingles. For better illustration, the relationships between the percentage improvement, compared to the samples with no singles, and shingle content are shown in Figure 3(b). It is clear that an increase in the shingle content increased the splitting strength, while the optimal improvement in compressive strength occurred at $10 \%$ shingle content.

The orientation of the shingles with respect to the directions of the principle strain is a major factor contributing to its reinforcing action. The best improvement is obtained when the shingles, especially long ones that can act as fibers, are oriented in the direction of the principle tensile strains. Much less effect occurs when the fibers are oriented in the direction of zero strain $[12,21]$. Therefore, it is clear that the performance of a new composite material depends on the number of shingle elements oriented in the favourable direction of tensile strains. As a result, increasing the number of shingle elements will result in a greater probability for a large numbers of shingles oriented in the direction of principle tensile strain and provide a reinforcing action. Therefore, a better improvement in splitting tensile strength 


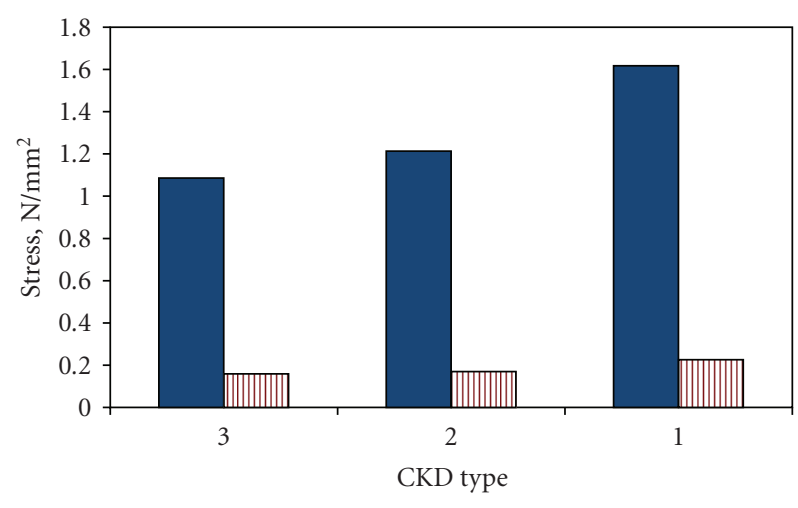

- Unconfined strength 凹 Spliting strength

(a)

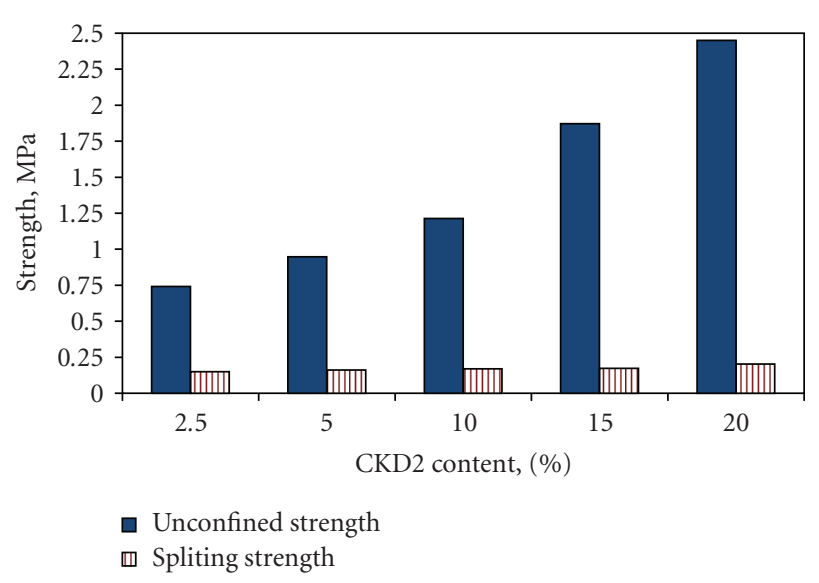

(b)

FIGURE 2: Effect of CKD on compressive and split tensile strengths: (a) different CKD types and (b) CKD2 contents (no shingles).

is expected when the number of shingle elements is larger. This was the case for the samples investigated in this study.

Figure 4 shows the effects of shingle size on strength. As noted, as the shingle size decreases, the compressive strength increases, while the splitting tensile strength decreases. A plausible explanation of these results is that increasing the sizes of shingles provides a greater opportunity for the shingle to act as reinforcement and reduce the initiation and propagation of cracks. In the case of compressive strength, the best performance was obtained with the small shingle size since the new composite material behaves as a homogenous and isotropic material due to the small difference in size between soil particles and the small shingle elements.

4.2. California Bearing Ratio. The CBR test was conducted on samples with and without shingles to evaluate the effect of shingles on soil stability. All samples were prepared without CKD. Figure 5(a) shows the relationship between CBR values versus shingle content of small shingle size. As noted, adding shingle, up to $10 \%$, increases the CBR compared to identical samples without shingles. The average increases in the CBR

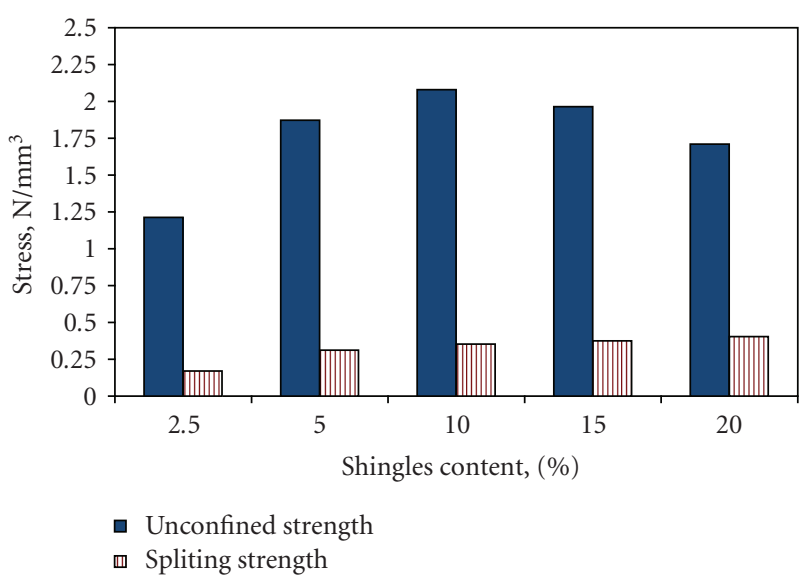

(a)

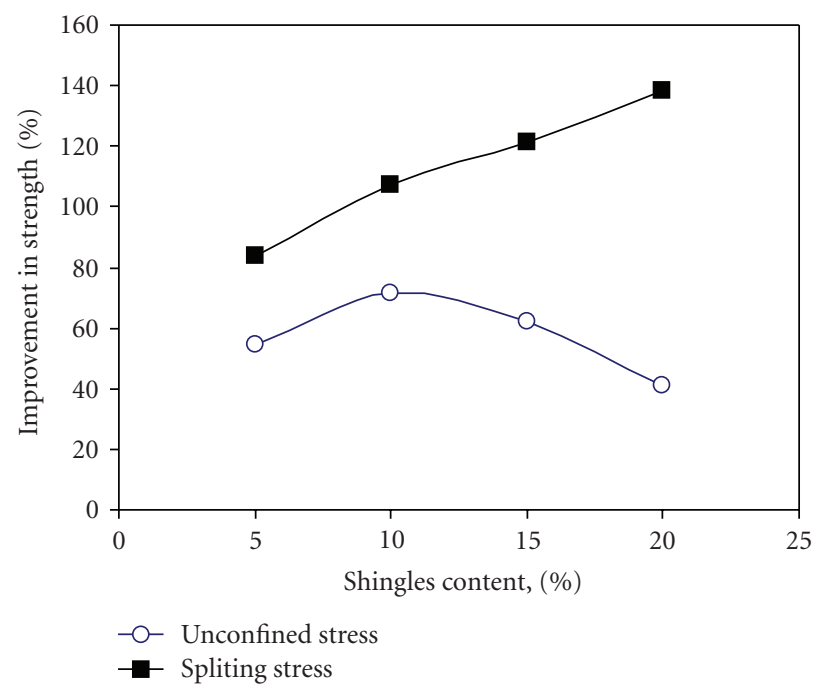

(b)

Figure 3: Effect of shingle content on compressive and tensile strengths: (a) different shingle contents (with 10\% CKD2) and (b) percentage improvement.

at $10 \%$ shingle were 2.4 and 2.2 times original value without shingles in the soaked and unsoaked conditions, respectively. The increase in stability of the stabilized soil with a shingle content of up to $10 \%$ could be attributed to the binding effect of the shingles. At levels beyond 10\%, the declining stability could be attributed to the reduction in the shear strength of the soil-shingle matrix due to the high shingle content. Due to their asphalt coating, shingle particles do not develop high friction forces with the soil particles and these result in reduced stability. Figure 5(b) shows the relationship between shingle size and CBR for samples containing 10\% shingles. It can be seen that the smaller size resulted in larger improvements in the CBR in both the soaked and unsoaked conditions. It seems that, for the same shingle content, the smaller the size, the larger the number of shingle elements. These elements are distributed homogeneously within the soil sample and provide better binding of the soil particles. 


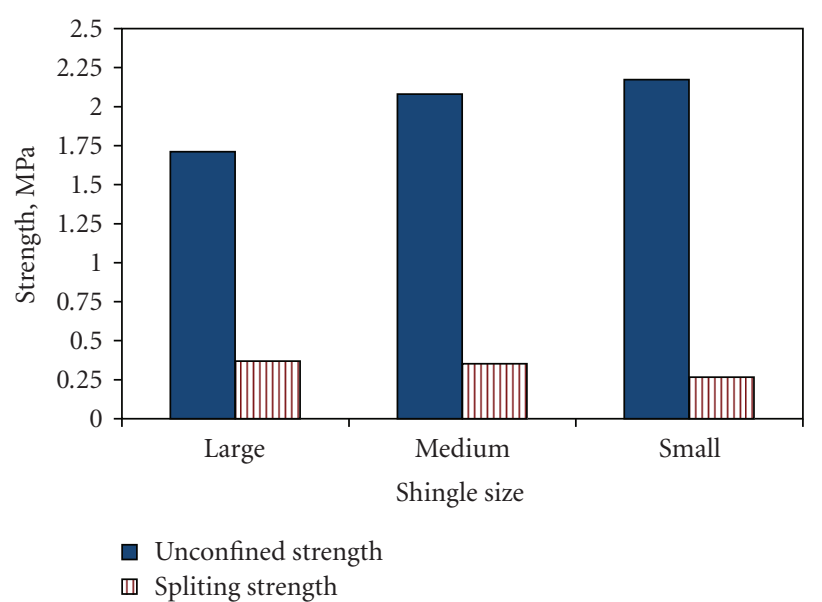

(a)

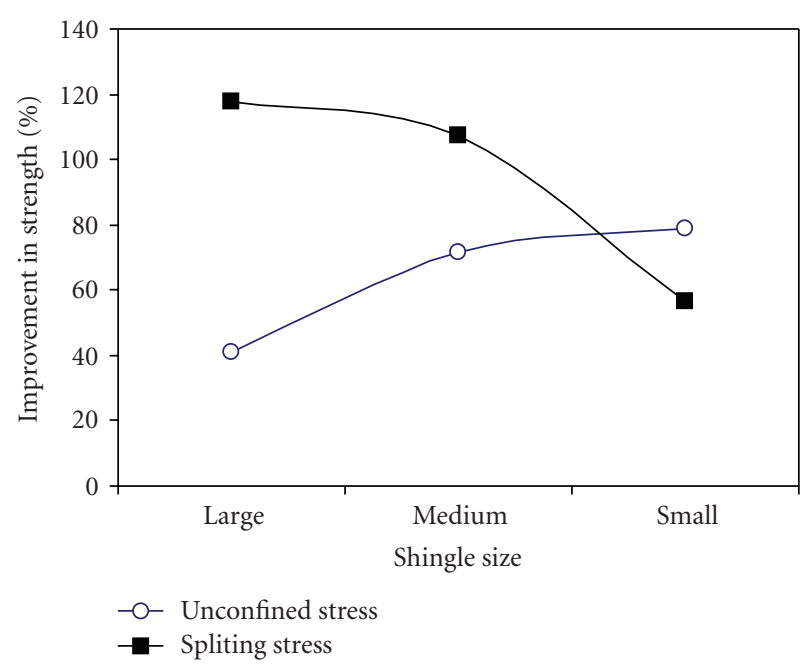

(b)

FIGURE 4: Effect of shingle size on compressive and tensile strengths: (a) different shingle sizes (with 10\% CKD2) and (b) Percentage improvement.

On the other hand, larger-size elements may act as a slippage surface resulting in a lower CBR.

4.3. Capillary Rise. Frost heave is an important measure that needs to be considered when evaluating soils for road works. The stability of soils for roads, railroads, airfields, buildings, underground storage, and pipeline facilities in cold regions critically depends on frost susceptibility [22]. Frost heave results primarily from the formation of segregated ice lenses in soil and secondarily from volumetric expansion of water during freezing. A source of water is the most important condition that contributes to frost heave which takes the form of an uplift pressure that causes cracks in pavements. In this study, the capillary rise is represented by the time it takes for the water to reach a certain height within the sample or the height of the water after a certain period of time. The longer the time or the smaller the height, the lower the capillary rise. Figure 6(a) shows the height of the capillary

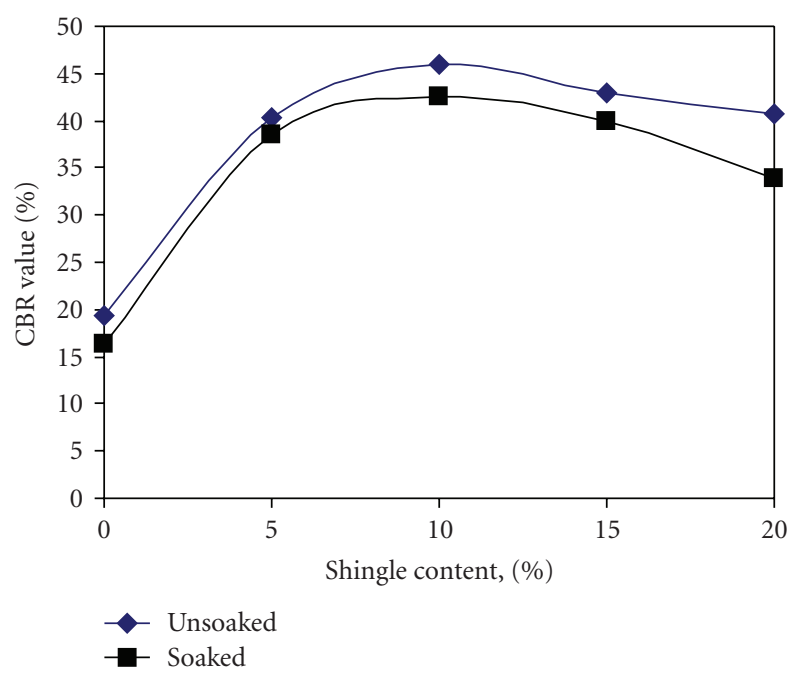

(a)

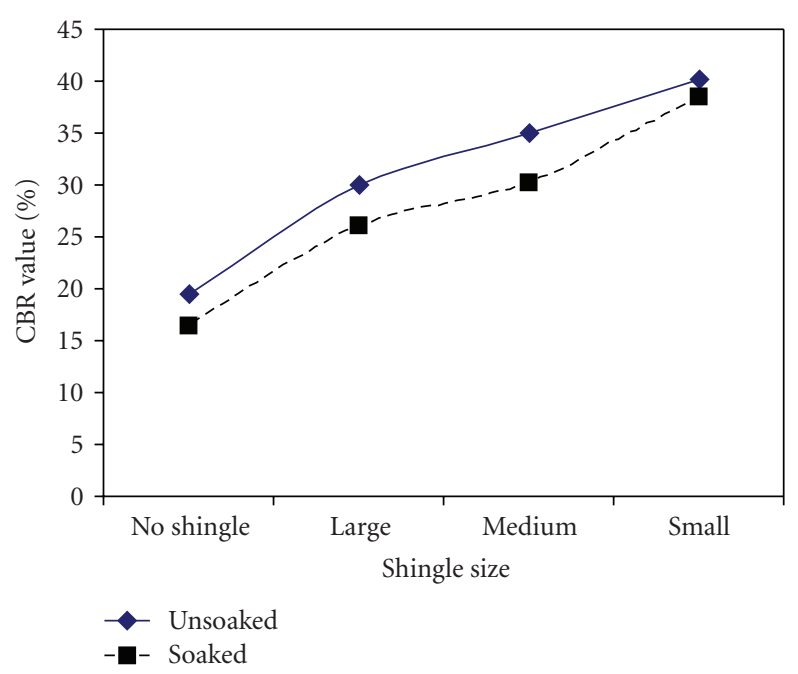

(b)

FIGURE 5: CBR results: (a) different shingle contents (small-size shingles and no CKD) and (b) different shingle sizes (5\% shingle and no CKD).

rise versus the time in seconds for a soil containing 10\% CKD and different levels of medium shingles. Figure 6(b) shows the capillary rise for samples with different size of shingles at a constant shingle and CKD contents of $10 \%$.

It is clear from these results that the addition of shingles significantly reduced the capillary rise of the stabilized soil. The time required for the water to reach a certain height within the sample increased as the shingle content increases. It is also clear from Figure 5 that there is no substantial difference between the values of the capillary rise within the first $20 \%$ of the sample height. After that, however, the difference became significant. The shingle size did not have much effect on the capillary rise as shown in Figure 6(b). The reduced capillary rise in the samples modified with shingles is attributed to the small contact angle between the water and the surface of the shingles which is coated with asphalt 


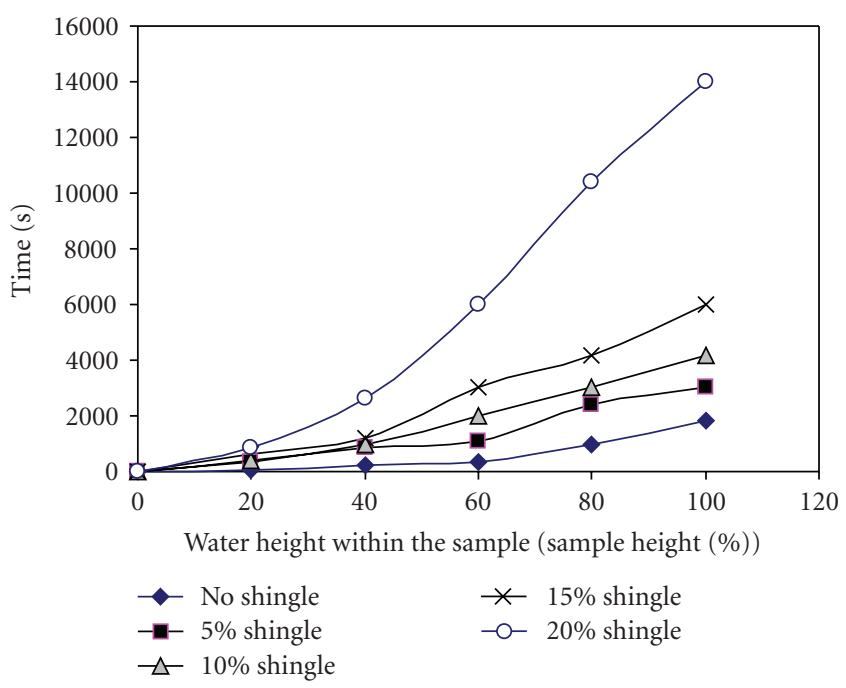

(a)

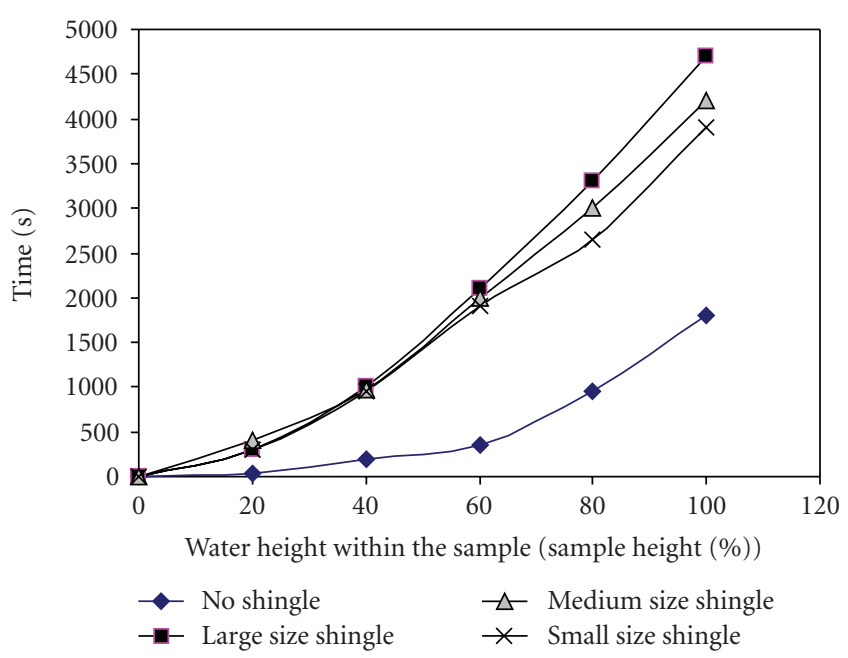

(b)

FIGURE 6: Capillary rise time required for different percentage heights: different shingle contents $(10 \%$ CKD and medium shingle size) and (b) different shingle sizes (10\% CKD and 10\% shingle).

cement. This reduces the ability of the water to rise in the pores of the soil. The data presented show that using waste shingle as a reinforcing material has a good effect on reducing the capillary rise by increasing the time required for the water to reach a certain height within the sample. This is of special importance in cold climate applications that involve frost susceptible soils. Reducing the capillary rise in such soils reduces the rate at which the water reaches the freezing front and hence reduces the formation of the ice lenses that lead to frost heave and spring breakup.

4.4. Permeability. Permeability is considered one of the important measures for evaluating the feasibility of using shingles to stabilize subgrade materials. The shingles should not decrease the permeability of the subgrade as this may increase its frost susceptibility. The relationship between

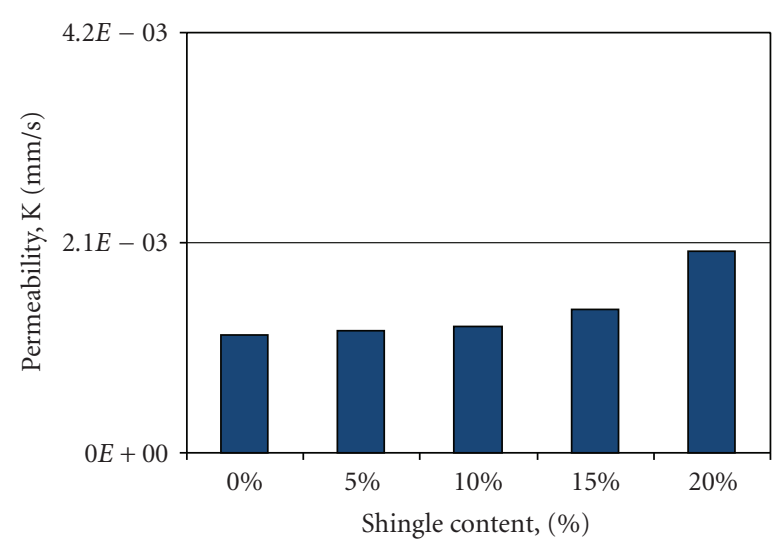

(a)

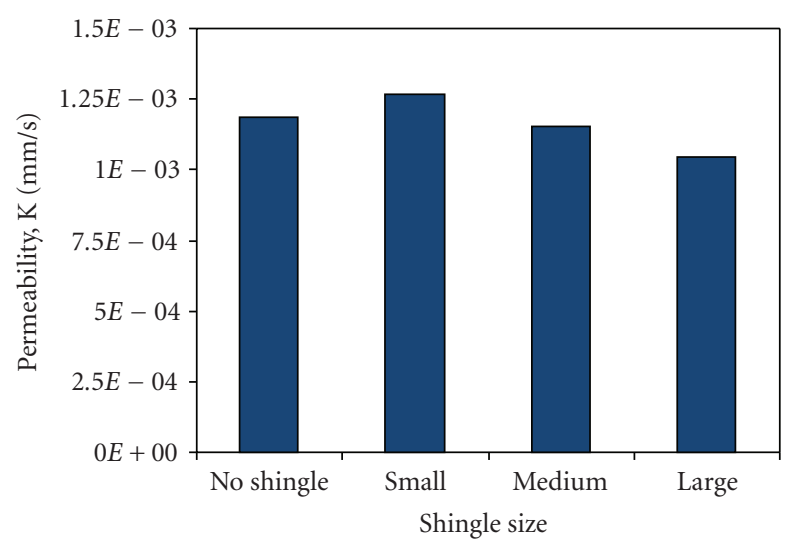

(b)

Figure 7: Permeability for different shingle sizes: (a) small shingle size and (b) $10 \%$ shingle.

permeability and shingle content (small size) is shown in Figure 7(a). As noted, the addition of shingles, especially up to $15 \%$, does not have a noticeable effect on permeability.

The relationship between permeability and shingle size is shown in Figure 7(b) for samples with 10\% shingle content. The results show that shingle size does not have a substantial effect on permeability. Generally, it can be concluded that the shingle content that enhances soil properties (up to $10 \%$ ) does not have an adverse effect on permeability. An insignificant decrease in permeability was observed in the case of large shingle size compared to other sizes and untreated samples. This is due to the fact that larger shingles result in increasing the water path around the elements (shingles). This in turn results in small reduction in the permeability.

\section{Conclusions}

This paper has demonstrated the benefits of using CKD and RAS in enhancing the performance of silty subgrade soils. The enhanced stability would result in pavements of smaller thickness or longer service life. In addition, the reduced capillary rise will reduce the possibility of 
cracking resulting from frost heave or spring breakup. These performance-related benefits, besides the environmental and economic benefits associated with the utilization of these wastes and co-generated products in construction, make the use of these wastes in subgrade applications very attractive and support sustainable development in construction. The specific findings of this research are the following.

(1) The RAS and CKD materials were found to be effective in enhancing the performance of fine grained subgrade.

(2) The compressive strength increased with the increase in the CKD content. On the contrary, CKD had no effect on the splitting tensile strength. Adding shingles increased both the compressive and splitting strengths. However, the shingles had a more significant positive effect on the splitting tensile strength compared to the compressive strength.

(3) The results showed that using a 10\% shingle content passing sieve no. $4(4.75 \mathrm{~mm})$ and retained on sieve no. $8(2.36 \mathrm{~mm})$ resulted in the best results in terms of CBR (stability), tensile strength, and compressive strength. The permeability of the samples containing $10 \%$ shingles was very close to that of the untreated materials.

(4) The large shingle size increased the splitting tensile strength, while the small shingle size had a better effect on the compressive strength. While RAS has a noticeable positive effect on the tensile strength, CKD has the same positive effect on compressive strength. Depending on the application, one or both of these co-generated products can be used.

(5) The addition of shingles reduced the capillary rise in sility soil which would reduce the possibility of ice lens formation in frost-susceptible soils.

\section{Acknowledgment}

Funding of this research project is provided through a Discovery Grant from the Natural Sciences and Engineering Research Council of Canada (NSERC). The authors appreciate the financial support of this organization.

\section{References}

[1] Canadian Asphalt Shingles Manufacturers' Association, "Asphalt shingles organic or glass," Technical Bulletin 20, 2000, http://www.casma.ca/en/bulletin_20.shtml.

[2] J. Surwillo, C. Grodinsky, and N. Plunkett, "Performance of recycled asphalt shingles for road applications," Final Report, Vermont Agency of Natural Resources, Montpelier, VT, USA, 2002.

[3] ASMI, "Enhanced recovery of roofing materials," Tech. Rep., pp. 20-21, Athena Sustainable Materials Institute, Merrickville, Canada, 2007, http://www.athenasmi.ca/projects/docs/ Athena_Roofing_Study_EN.pdf.

[4] W. Thaha, Development of controlled low strength materials using cement kiln dust, M.S. thesis, Civil Engineering Department, Ryerson University, Toronto, Canada, 2005.
[5] V. J. Marks and G. Petermeier, "Let me shingle your roadway," Interim Report Research Project HR-2079, Iowa Department of Transportation, Ames, Iowa, USA, 1997.

[6] F. Hooper and M. W. Allen, "Effects of reclaimed asphalt shingles on engineering properties of soils," in Proceedings of the ASCE Civil Engineering Conference and Exposition, A. Aydilek and J. Wartman, Eds., ASCE Geotechincal Special Publication, no. 127, pp. 137-149, 2005.

[7] S. Rajendran and J. A. Gambatese, "Solid waste generation in asphalt and reinforced concrete roadway life cycles," Journal of Infrastructure Systems, vol. 13, no. 2, pp. 88-96, 2007.

[8] A. Ibrahim, S. Faisal, and N. Jamil, "Use of basalt in asphalt concrete mixes," Construction and Building Materials, vol. 23, no. 1, pp. 498-506, 2009.

[9] P. Kumar and S. P. Singh, "Fiber-reinforced fly ash subbases in rural roads," Journal of Transportation Engineering, vol. 134, no. 4, pp. 171-180, 2008.

[10] L. Kraszekski and J. Emery, "Use of cement kiln dust as a filler in asphalt mixes," in Proceedings of the ORF/CANMET Symposium on Mineral Fillers, Ontario Research Foundation and Canada Center for Mineral and Energy Technology, Toronto, Canada, 1981.

[11] N. N. Khoury and M. M. Zaman, "Environmental effects on durability of aggregates stabilized with cementitious materials," Journal of Materials in Civil Engineering, vol. 19, no. 1, pp. 41-48, 2007.

[12] A. Ahmed, Utilization of shredded waste tires in the strengthening of unpaved roads over soft clay, Ph.D. thesis, Civil Engineering Department, Faculty of Engineering, El-Mina University, El-Minia, Egypt, 2004.

[13] S. Arora and A. H. Aydilek, "Class F fly-ash-amended soils as highway base materials," Journal of Materials in Civil Engineering, vol. 17, no. 6, pp. 640-649, 2005.

[14] G. J. Foose, C. H. Benson, and P. J. Bosscher, "Sand reinforced with shredded waste tires," Journal of Geotechnical and Geoenvironmental Engineering, vol. 122, no. 9, pp. 760-767, 1996.

[15] M. Ghazavi and M. A. Sakhi, "Influence of optimized tire shreds on shear strength parameters of sand," International Journal of Geomechanics, vol. 5, no. 1, pp. 58-65, 2005.

[16] F. A. Hassona, M. A. Hassan, M. D. Hashem, N. A. Marei, and A. A. Aly, "Improvement of soft clay characteristics using sand cushion reinforced with shredded waste tire," in Proceedings of the 1st International Conference on Engineering for Waste Treatment, Beneficial Use of Waste and by-Products, Ecole des Mines d'Albi-Carmaux, Albi, France, 2005.

[17] J. C. Morel and J. P. Gourc, "Mechanical behaviour of sand reinforced with mesh elements," Geosynthetics International, vol. 4, no. 5, pp. 481-508, 1997.

[18] K. Sobhan and M. Mashnad, "Mechanical stabilization of cemented soil-fly ash mixtures with recycled plastic strips," Journal of Environmental Engineering, vol. 129, no. 10, pp. 943947, 2003.

[19] N. C. Consoli, J. P. Montardo, P. D. Marques Prietto, and G. S. Pasa, "Engineering behavior of a sand reinforced with plastic waste," Journal of Geotechnical and Geoenvironmental Engineering, vol. 128, no. 6, pp. 462-472, 2002.

[20] L. Chen and D.-F. Lin, "Stabilization treatment of soft subgrade soil by sewage sludge ash and cement," Journal of Hazardous Materials, vol. 162, no. 1, pp. 321-327, 2009.

[21] S. M. Salem, An investigation of the effect at geogrid inclusions on sand behaviour in triaxial and model tests, Ph.D. thesis, 
Civil Engineering Department, Cairo University, Cairo, Egypt, 1989.

[22] G. M. Marion, "Freeze-thaw processes and soil chemistry," Special Report 95-12, US Army Corps of Engineers, Cold Regions Research \& Engineering Laboratory, Washington, DC, USA, 1995. 

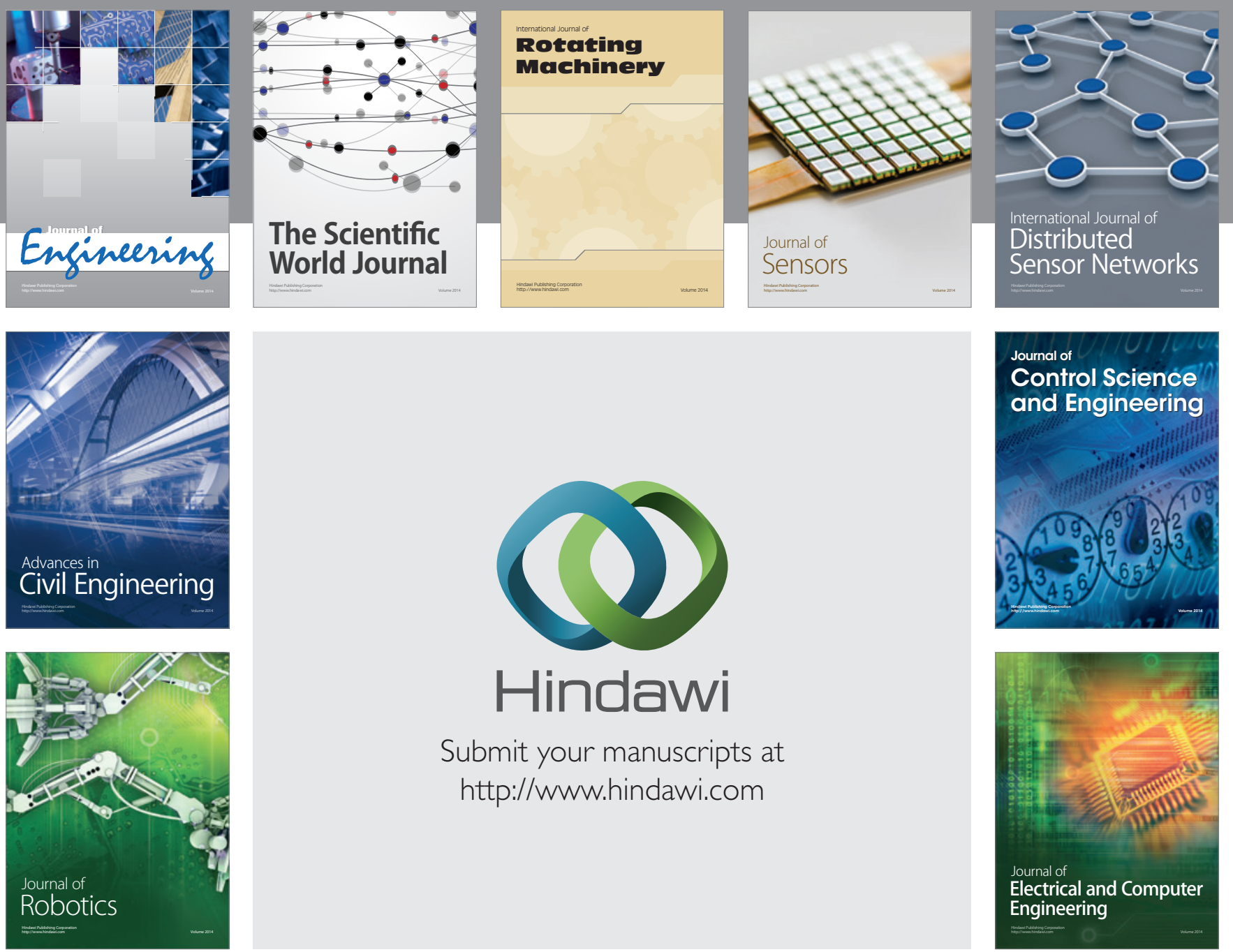

Submit your manuscripts at

http://www.hindawi.com
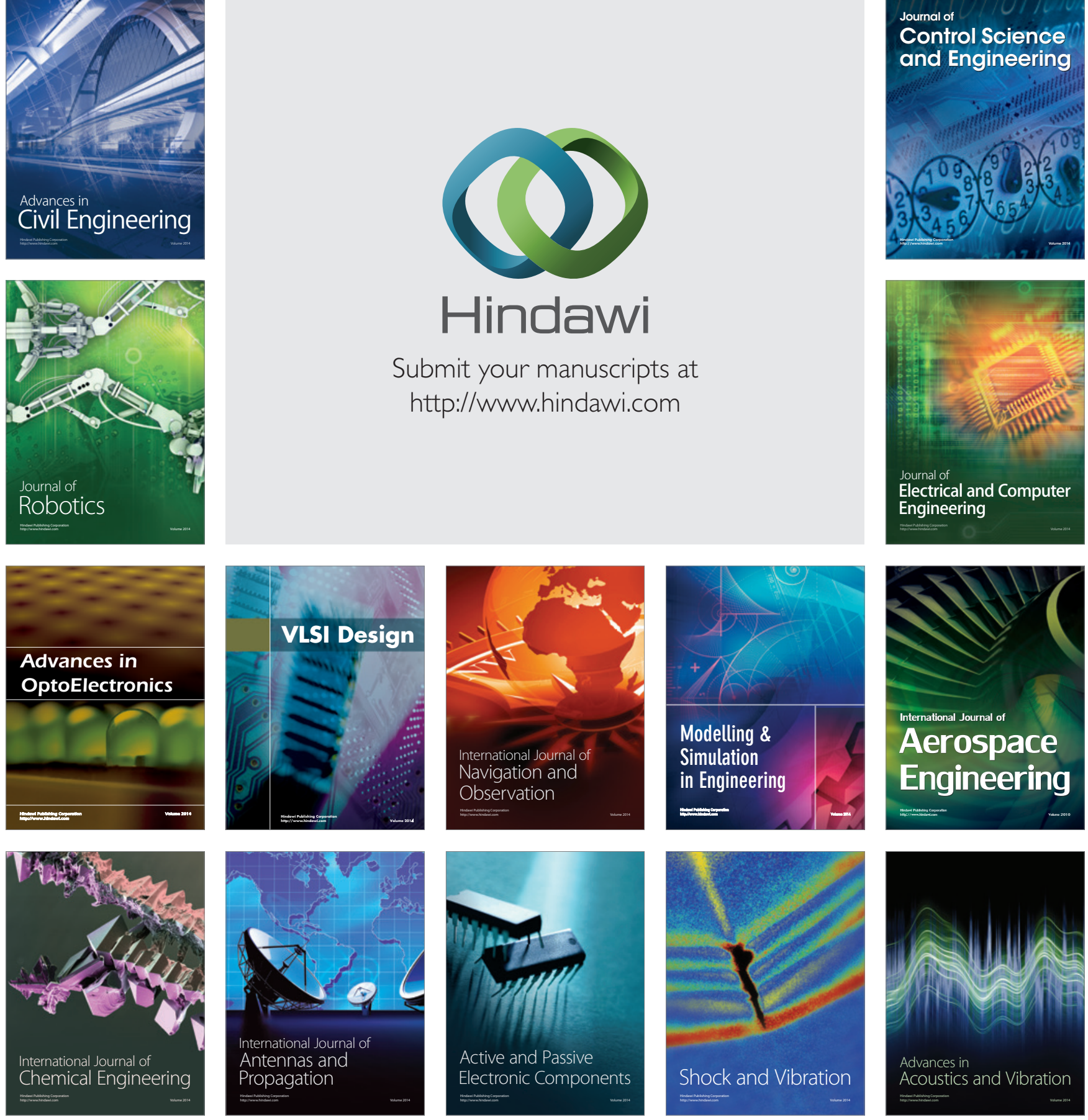